\title{
NASA outlines path to Mars
}

\section{Washington}

PRESIDENT George Bush's vision of lunar and martian exploration, made public on the twentieth anniversary of Apollo 11's Moon landing (see Nature 340, 249; 1989), is so far no more than a vision. Trying to inject some reality into these grand schemes, the National Aeronautics and Space Administration (NASA) last month released a report that offers five exploration strategies.

But the report, the result of a threemonth collaboration by all of NASA's divisions, confines itself to making suggestions, which come without price tags, that the president's National Space Council might wish to adopt with a view to working them up into detailed plans.

In the first strategy, the astronauts return to the Moon in 2001 and occupy a lunar base permanently in the following year; the first mission to Mars is in 2015. But this tight schedule depends on accelerating the development of the space station so that its assembly is complete by 1997 , two years earlier than planned.

Financial problems have already forced NASA to plan a new 'rephased' space station programme which stretches out several parts of the programme by six months. The Shuttle-C, a new cargocarrying launch vehicle needed to ferry space station components from Earth, is the only new vehicle that could be ready in time to meet this schedule.

In the second strategy, the first lunar mission is also planned for 2001, but the first human Mars landing is brought forward to 2011 , delaying scientific research on the Moon but accelerating it on Mars. This would require the concentration of funds in the first decade of the next century so that hardware for both the lunar and the martian outposts could be developed in parallel.

NASA also outlines a third possible plan which is similar to this one, and a fourth which delays the major milestones by two to three years.

In the final strategy, all the major steps in the programme are delayed: the return to the Moon is in 2004; the first landing on

\section{Too many cooks preserve diversity}

\section{Washington}

THE preservation of biological diversity in the United States and worldwide is a project with many supporters. Paradoxically, that seems to be causing trouble. Earlier this year, the National Science Foundation (NSF) argued that, because of its longstanding support of ecological research, it should be given a role in national efforts to document and preserve plant and animal species (see Nature 340,$585 ; 1989$ ). Meanwhile, plans have been stirring in Congress to set up a National Center for Biological Diversity with the Smithsonian Institution at its helm, but at a congressional hearing last month Robert Jenkins, vice-president for science programmes at the Nature Conservancy argued that his organization ought to play the lead role because of its past and continuing efforts in species preservation.

The purpose of the hearing, before a subcommittee of the House of Representatives committee on Merchant Marine and Fisheries, was to discuss two principal questions embodied in proposed legislation: the establishment of a national centre to coordinate data collection and research concerning biodiversity, and to incorporate into the charter of various federal agencies language to make species preservation a particular concern. At present, only the National Forest Service (NFS) has such language in its charter. David Wilcove, an ecologist with the Wilderness Society, argued that the NFS had not traditionally put conservation issues high on its list of priorities, and cited the case of the northern spotted owl, which inhabits forests of the Pacific northwest: NFS forest management, Wilcove claimed, had given over such quantities of the owl's habitat to logging that the Fish and Wildlife Service, another federal agency, was now arguing for the owl to be listed as an endangered species.

It was agreed by all that the Endangered Species Act was ineffectual in preserving general biodiversity, and that some mechanism was needed to enforce conservation regulations before species were threatened to the point of extinction. But while there was general satisfaction at the hearing with the idea of a national centre run by the Smithsonian, Jenkins protested that the Nature Conservancy, a private non-profit organization, had been running such a programme on a small scale for many years.

Its Heritage Program, he said, was ready to receive federal support that would expand it into the National Center for Biological Diversity of proposed legislation, and suggested an amendment of the law that would give the Nature Conservancy the appropriate leading role. But Jenkins seemed to be in a minority of one: George Davis of the Academy of Natural Sciences of Philadelphia said there was "plenty the Nature Conservancy is not doing" and that only a suitable federal body would have the authority to enforce interagency collaboration.

\section{Belgium joins EMBL}

\section{Heidelberg}

BELGIUM has become the fifteenth member of the European Molecular Biology Laboratory (EMBL), director Lennart Philipson announced last week. The additional support of roughly DM1.5 million $(\$ 840,000)$ a year, plus an entry fee, is a modest addition to EMBL's budget, but the new funds, says Philipson, will allow EMBL to increase the number of fellowships it awards. The exact use of the money must be determined by the EMBL council. Like all member states, Belgium will contribute to EMBL in proportion to its gross domestic product. Its yearly payment will provide about 3.1 per cent of the DM49 million (\$28 million) EMBL budget.

Steven Dickman

Mars is in 2016 and a permanent Mars outpost would not be ready until 2027 . Research on the Moon would begin around 2007 with Earth-controlled geological and geophysical exploration, establishment of the astronomical telescope arrays and human biomedical research in the lunar laboratory. In 2022, there would be a piloted flight to the far side of the Moon for geological exploration and to set up a radioastronomy and geophysical observatory.

To carry out this programme, NASA says it will need a substantial increase in staff numbers, from the 24,000 permanent staff it has at present. But it complains in the report about the "antiquated" federal employment structure which keeps salaries and benefits low, making it difficult to recruit high-quality scientific and technical personnel in the increasingly competitive marketplace.

NASA also wants to change the rigid budget process which allocates funds on a two-year basis, resulting in short-term planning and instability. When NASA was established it was granted "no year" funds which it did not have to spend within an established time period, and it had greater flexibility to alter programmes, to accept gifts, to buy property and to enter into contract on any terms and conditions it deemed necessary. With new legislation and regulations, these powers have been gradually eroded, but NASA says that the complexity of a 30-year lunar and Mars exploration programme necessitates change. NASA has not yet attempted a programme of this size, requiring such long-term development, and unless existing legal regulatory structures are changed, there will be "a severe penalty in schedules, resources and efficiencies" it says.

Christine McGourty

\section{Correction}

The outgoing president of the South African Council for Scientific and Industrial Research is Dr Chris Garbers (see Nature 342, 334; 1989). 